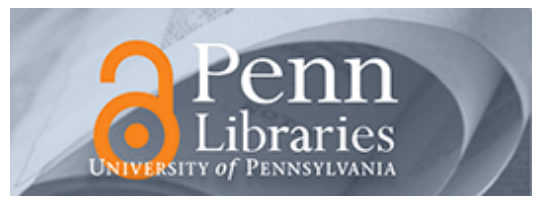

University of Pennsylvania

ScholarlyCommons

Management Papers

Wharton Faculty Research

$10-2009$

\title{
A Decision-Making Perspective to Negotiation: A Review of the Past and a Look to the Future
}

Chia-Jung Tsay

University of Pennsylvania

Max H. Bazerman

Follow this and additional works at: https://repository.upenn.edu/mgmt_papers

Part of the Business Administration, Management, and Operations Commons

\section{Recommended Citation}

Tsay, C., \& Bazerman, M. H. (2009). A Decision-Making Perspective to Negotiation: A Review of the Past and a Look to the Future. Negotiation Journal, 25 (4), 467-480. http://dx.doi.org/10.1111/

j.1571-9979.2009.00239.x

This paper is posted at ScholarlyCommons. https://repository.upenn.edu/mgmt_papers/40

For more information, please contact repository@pobox.upenn.edu. 


\title{
A Decision-Making Perspective to Negotiation: A Review of the Past and a Look to the Future
}

\begin{abstract}
Over the past quarter century, the decision-analytic approach to negotiation has seen the development of a better dialogue between the descriptive and the prescriptive and has also attracted the interest of both academics and practitioners. Researchers have built upon the work in behavioral decision theory, examining the ways in which negotiators may deviate from rationality. The 1990s brought a renewed interest in social factors, as work on social relationships, egocentrism, attribution and construal processes, and motivated illusions was incorporated into our understanding of negotiations. Several promising areas of research have emerged in recent years, drawing from other disciplines and informing the field of negotiations, including work on the influence of ethics, emotions, intuition, and training.
\end{abstract}

\section{Keywords}

negotiation, bargaining, decision analyses, biases, ethics, affect, intuition, negotiation training

Disciplines

Business Administration, Management, and Operations 


\section{A Decision-making Perspective to Negotiation: A Review of the Past and a Look into the Future}

By Chia-Jung Tsay and Max H. Bazerman

Chia-Jung Tsay is a doctoral student in organizational behavior at Harvard Business School in Boston. Her e-mail address is ctsay@hbs.edu.

Max H. Bazerman is the Jesse Isidor Straus Professor of Business Administration at Harvard Business School in Boston. His e-mail address is mbazerman@hbs.edu.

\footnotetext{
Abstract

Through the decision-analytic approach to negotiations, the past quarter century has seen the development of a better dialog between the descriptive and the prescriptive, as well as a burgeoning interest in the field for both academics and practitioners. Researchers have built upon the work in behavioral decision theory, examining the ways in which negotiators may deviate from rationality. The 1990s brought a renewed interest in social factors, as work on social relationships, egocentrism, attribution and construal processes, and motivated illusions was incorporated into our understanding of negotiations. Several promising areas of research have emerged in recent years, drawing from other disciplines and informing the field of negotiations, including work on the influence of ethics, emotions, intuition, and training.
} 
Key words: negotiation, bargaining, biases, ethics, affect, intuition, negotiation training

\section{Introduction}

In the early 1980s, Cambridge, Massachusetts, was a hotspot on the negotiations front. Scholars from different disciplines started interacting with each other to explore exciting new concepts, and the field took a big leap forward with the creation of the Program on Negotiation, an interdisciplinary, multi-college research center based at Harvard University. Very quickly, Roger Fisher and William Ury’s (1981) popular book Getting to Yes had a pronounced impact on how practitioners think about negotiations. On a more scholarly front, a related, yet profoundly different change was occurring. Howard Raiffa’s (1982) book The Art and Science of Negotiation was transforming how researchers would think about and conduct empirical research for the next quarter century.

\section{The Decision-analytic Approach}

Offering an alternative to the game-theoretic study of negotiation, which takes place in a world of “impeccably rational, supersmart people,” Raiffa developed a decision-analytic approach to negotiations, one that described how “erring folks like you and me actually behave,” rather than "how we should behave if we were smarter, thought harder, were more consistent, were allknowing” (Raiffa 1982: 21). Raiffa focused on giving the best available advice to negotiators 
involved in real conflicts with real people. His approach offers prescriptions to negotiators, but calls for descriptive research to assess the likely behavior of their counterparts. His colleagues David Lax and James Sebenius (1986) further developed this approach in their book The Manager as Negotiator.

From a research perspective, Raiffa’s approach presented an even greater contribution in opening up the decision-analytic approach to negotiations, which has been at the heart of the negotiation training that has proliferated in management, public-policy, and law schools over the past twenty-five years. Raiffa’s work provided the basic analytic structure for negotiation courses and helped to create some of the most popular new courses in the management curriculum.

While focusing on the development of a prescriptive model, Raiffa explicitly realized the importance of developing accurate descriptions of one's opponent, rather than assuming him or her to be fully rational. The recognition that negotiators need advice implicitly acknowledges that negotiators do not always intuitively act rationally. Moreover, Raiffa laid the groundwork for a dialogue between prescriptive and descriptive negotiation researchers. His work called for descriptive research that would help a focal negotiator anticipate the likely behavior of an opponent. At the same time, decision analysts have acknowledged that decision biases limit negotiators’ ability to follow such prescriptive advice. 


\section{Individual Biases in Negotiation}

In response to Raiffa's prescriptive structure, behavioral decision researchers started to address the fundamental questions it raised (Bazerman and Neale 1992; Thompson 2005; Bazerman and Moore 2008). Behavioral decision researchers identified the systematic ways in which people depart from rationality, to identify the barriers to the focal negotiator and to identify what could be expected from other parties. The concept of "rationality" in Raiffa's writing, and in the work of behavioral decision researchers, did not make any assumptions about what the negotiator valued, only that they optimally pursued their own objectives.

Building off of work in behavioral decision theory (Tversky and Kahneman 1974;

Kahneman and Tversky, 1979), a number of deviations from rationality have been identified that can be expected in negotiations. Researchers found, for example, that negotiators tend to be inappropriately affected by the positive or negative frame in which they view risks (Neale and Bazerman 1985; Bazerman, Magliozzi, and Neale 1985), to anchor their numeric estimates in negotiations -on irrelevant information such as arbitrary numbers or manipulated listing prices (Tversky and Kahneman 1974; Northcraft and Neale 1987)---addressed as above, to rely disproportionately on readily available information at the expense of critical but less salient information (Neale 1984), and to be overconfident about the likelihood of attaining outcomes that favor themselves (Bazerman and Neale 1982; Neale and Bazerman 1985). 


\section{Competitive Biases in Negotiation}

This application of behavioral decision research soon developed into a search for additional biases that might be created by the competitive nature of negotiations. Soon, we learned that negotiators tend to assume that negotiation tasks are fixed-sum (the mythical fixed-pie), to miss opportunities for mutually beneficial tradeoffs between the parties (Bazerman, Magliozzi, and Neale 1985); to escalate commitment to a previously selected course of action when it is no longer the most reasonable alternative (Bazerman and Neale 1983); to overlook valuable, available information by failing to consider the opponent's cognitive perspective (Samuelson and Bazerman 1985; Bazerman and Carroll 1987) and strengths and weaknesses (Radzevick and Moore 2008), and to retroactively devalue any concession made by one’s opponent (Ross and Stillenger 1991). This new perspective, which developed Raiffa's analytic structure through the lens of behavioral decision research, prompted a large body of research that integrated analytic structures with descriptively accurate models of human cognition.

\section{Bringing Social Psychology Back to the Table}

While the behavioral decision perspective had a significant influence on the scholarship and practice of negotiation, it was soon criticized for taking an overly narrow view of the negotiation process-(e.g., Barley 1991; Greenhalgh and Chapman 1995). Namely, some argued that the perspective missed several key social components that are critical to the practical task of negotiating more effectively. By the late 1990s and into the new millennium, researchers began 
to incorporate many of these missing social factors within the behavioral decision perspective, including social relationships, egocentrism, attribution and construal processes, and motivated illusions.

\section{Social Relationships}

The role of relationships had a deep history in the early decades of negotiation research (e.g., Follett 1940; Walton and McKersie 1965; Rubin and Brown 1975)). In the 1990s, relationships returned as a variable that affects the quality of negotiators' decisions and the wisdom of the outcomes they negotiate. At an individual level, George Loewenstein, Leigh Thompson, and Max Bazerman (1989) found that disputants’ reported preferences for monetary payoffs were greatly influenced by payoffs to and relationships with their hypothetical counterparts. People often care far more about their relative than their absolute outcomes, preferring Pareto-inefficient outcomes in order to avoid being comparatively disadvantaged. For example, people were found to prefer an outcome of seven dollars for themselves and seven dollars for the other side over an outcome of eight dollars for themselves and ten dollars for the other party (Blount and Bazerman 1996).

At a dyadic level, Kathleen Valley , Joseph Moag, and Max Bazerman (2002) showed that behaviors that appear irrational from the individual perspective may be rational from the perspective of the dyad. This work demonstrated that, when given the opportunity to communicate directly, negotiators take actions that often appear irrational in their individual 
decision making, but reach dyadic outcomes that outperform game-theoretic models. At the market level, Ann Tenbrunsel and her colleagues (1999) argued that people too often "satisfice” (March and Simon 1958) by dealing with other people they already know, even when a more open search would produce more successful results.

\section{Egocentrism in Negotiation.}

Often, when parties disagree about what is fair, each side assumes that the other party is intentionally overstating its case. In contrast, research has documented that it is extremely common and predictable for parties to overweight views that favor themselves, a phenomenon that results in a motivational bias (Babcock and Loewenstein 1997; Diekmann et al. 1997) to perceive what is fair through a self-serving lens. Thompson and Loewenstein (1992) showed that negotiators are egocentric and that the more egocentric parties are, the higher the likelihood of impasse. This result has been well-replicated in studies that used financial incentives for performance and across negotiation contexts (Babcock et al. 1995). In addition, Thompson and Loewenstein (1992) found that the provision of additional (neutral) information actually increases egocentrism. Participants who received more information tended to make more extreme estimates about what would be a fair outcome. Finally, study participants also showed self-serving recall bias, remembering better those facts that favored themselves. David Messick and Keith Sentis (1983) argued that preferences are determined through reflection, a process that is vulnerable to bias. Ambiguous situations create uncertainty about fairness, and negotiators 
tend to interpret fairness in ways that favor themselves.

\section{Motivated Illusions in Negotiation}

Human beings see themselves, their side of a negotiation, and the future in a considerably more positive light than more realistic assessments would justify (Taylor 1989; Kramer 1994). We perceive ourselves as being better than others on desirable attributes, and we make unrealistically positive self-evaluations (Messick et al. 1985). In negotiations, Roderick Kramer and his colleagues (1993) showed that 68 percent of MBA students in a negotiation class predicted that their bargaining outcomes would fall in the top 25 percent of the class.

Negotiators’ optimism can be traced to the overestimation of their ability to control uncontrollable events (Kramer 1994). In prisoner dilemma games, negotiators behave as if their decisions will control the simultaneous decisions of the other party, even when that expectation is logically impossible (Shafir and Tversky 1992; Morris et al. 1998). One reason parties cooperate in one-shot prisoner dilemma games is the illusion that their own cooperation will

motivate the other side to cooperate. Positive illusions can also have social costs: Kramer (1994) found that unsuccessful negotiators denigrate their more successful counterparts by attributing their success to uncooperative and unethical bargaining tactics.

\section{Attributional Processes in Negotiation.}


Negotiators play the negotiation game they perceive, rather than some objective specification of a game. As a result, attributional processes are critical to understanding the decisions of negotiators. Lee Ross and Andrew Ward (1996) found negotiators tend to exaggerate the polarization between two groups in conflict. In this work, pro-life and pro-choice advocates responded to a variety of questions surveying their own attitudes about abortion, as well as those of members of the other partisan group. Each side overestimated the differences between attitudes held by the two sides.

In a related research stream, Kramer (1994) found that, when the basis for others' behavior is ambiguous, people will tend to attribute it to sinister motivations. Furthermore, when their opponents offer friendly explanations for their behavior, negotiators discount them to the extent that more sinister explanations are plausible (Robinson and Friedman 1995). Such attributions are likely to engender blame and hostility, making agreement difficult (Keltner and Robinson 1993).

Lee Ross and Steve Samuels (1993) found that decisions in a prisoner's dilemma game could be drastically influenced by the name assigned to that game. People who played "The Community Game” cooperated approximately twice as frequently as participants who played an identical game entitled “The Wall Street Game” (Ross and Ward 1995). Similarly, Richard Larrick and SallyBlount (1997) showed that the presentation of an ultimatum game influences participants' behavior. When the objectively identical game was described as a social dilemma (mutual “claiming” of a shared resource) rather than an ultimatum game (a "proposed division” 
followed by "accepting” or "rejecting”), those who propose the division ("first movers") are more generous in their allocations, and those who "accept" or "reject" the division ("second movers”) are more tolerant of inequalities that favor the other player. Remarkably, second movers were three times more likely to accept allocations of zero for themselves when the game is described as a social dilemma (“claiming”) rather than an ultimatum game (“rejecting”/“accepting”) (Larrick and Blount 1997).

Collectively, a robust body of research has integrated insights from social psychology into a descriptive model of how negotiators make decisions. We are confident that much of this research will be further developed and expanded. We also see the opportunity for new research directions that will expand our understanding of the decisions of negotiators.

\section{Where Do We Go Next?}

As the field of negotiation develops and expands, we believe the decision perspective will continue to play a central role and that the areas of research reviewed above will continue to expand. We also see the seeds of some emerging trends. In this section, we preview some important new directions in negotiation research and practice.

\section{Ethics in Negotiation}

Ethical standards in negotiation are critical to understanding the nature of the negotiation game. 
A number of studies have evaluated the perceived permissibility of common bargaining tactics (Lewicki and Stark 1996; Menkel-Meadow and Wheeler 2004). The 1990s saw an active debate regarding the ethics of deception in negotiation. Some argued that deception is to be expected in negotiation and is morally acceptable (Strudler 1995). In contrast, others argued that deception is always morally regrettable (Dees and Cramton 1991, 1995) and have called for normative standards of negotiation behavior. More recently, attention has shifted toward understanding the psychology of ethics in the context of negotiation (Tenbrunsel 1998; Tenbrunsel and Messick 2004).

Because people egocentrically interpret what is fair in negotiation (Babcock and Loewenstein 1997), they can have different standards, based on whether they initiate the questionable behavior or if they are the victim of that behavior. Moreover, people develop these differential standards without conscious awareness (Banaji, Bazerman, and Chugh 2003). We see differing perceptions of the nature of ethical infractions as a significant cause of conflict. When one party views the other as unethical, and the other party sees herself as perfectly ethical, a significant barrier exists in moving their negotiated relationship forward. We believe that understanding the psychology of ethics and the degree to which people act unethically without their own awareness - our bounded ethicality - is an important direction for future work (Bazerman and Chugh 2006).

\section{Emotions}


Most early work on negotiations ignored emotion-relevant variables. A few notable exceptions included research that found that positive moods increased negotiators' tendency to select a cooperative strategy (Forgas 1998), increased their frequency of arriving at agreements that enhance joint gains (Barsade 2002), enhanced their ability to find integrative gains (Carnevale and Isen 1986), and helped negotiators avoid the development of hostility and conflict (Isen and Baron 1991). Angry negotiators were found to be less accurate than other negotiators at judging the interests of opponent negotiators and achieved lower joint gains (Allred et al. 1997). Some research also suggested that emotions played a functional role in negotiations (Damasio 1994; Keltner and Kring 1999; Barry 1999; Thompson et al. 1999).

Early studies found that anger makes negotiators more self-centered in their preferences (Loewenstein et al. 1989) and increases the likelihood that they will reject profitable offers in ultimatum games (Pillutla and Murnighan 1996). While earlier work has focused on helping negotiators become more aware of their emotions, such as anger and fear, with the goal of controlling them in critical negotiations (Adler, Rosen, and Silverstein 1998), more recent work has pointed out that even emotions not connected to the negotiations itself, or incidental emotions, can have a pronounced effect on behavior.

Some research on the role of emotions has focused on how affect influences judgments and behaviors through cognition, distinguishing between how positive versus negative moods lead to different information-processing strategies (Forgas and George 2001), primed associations, and bargaining strategies. Other researchers have argued against using the 
positive/negative distinction between emotions by pointing out that pronounced differences exist within these two categories. Examples of these emerging patterns can be seen in studies by Jennifer Lerner, Deborah Small, and George Loewenstein (2004). In the context of the endowment game, they found that when people experience incidental disgust, both buying and selling prices fall. In contrast, sadness triggered an implicit need for individuals to change their circumstances, creating a greater willingness to buy new goods or to sell goods they already had.

More recently, work has emerged that shows how emotions affect decision making in negotiations. Some exciting research pioneered by neuroscientists has delved into neural models of decision-making, where bioregulatory processes that may be expressed through emotions guide efficient decisions through both implicit and explicit knowledge (Damasio 1994; Bechara and Damasio 2005). Emotion scholars have also begun to more precisely examine the effects of generalized moods versus discrete emotions, as well as the nuanced effects of emotional intelligence skills on negotiation outcomes (Barsade and Gibson 2007). In addition, interest in facial dynamics has resurged; research indicates that we are sensitive to these dynamics and can quickly assess trustworthiness (Willis and Todorov 2006) and that these inferences mediate the effects of facial dynamics on cooperation (Krumhuber et al. 2007).

Finally, even as increasing proportions of social interaction now occur electronically and online, the impact of these media on decision-making has thus far been largely overlooked. Lacking the non-verbal cues that have allowed us to efficiently make sense of the complex information we are confronted with in every interpersonal interaction (Ambady and Rosenthal 
1992), and given previous research that suggests written negotiations show a higher incidence of impasse (Valley, Moag, and Bazerman 1998), there is much potential for research that examines the implications of this form of communication for negotiations. Some recent work suggest ways in which we may best harness the features of electronic negotiation to reach agreement more frequently (Hatta, Ohbuchi, and Fukuno 2007).

\section{Negotiator Intuition.}

Many negotiators trust their intuition. Much as we might be inclined to view a successful negotiator as one who is naturally gifted, we might also believe that we should privilege our gut feelings when it comes to facing and responding to an opponent negotiator. Keith Stanovich and Richard West (2000) have distinguished between System 1 and System 2 thought, characterizing the former as automatic, effortless, and influenced by emotions, and the latter as conscious, deliberate, and systematic. While we may believe we have control over how we think about situations, when it comes to the most important and complex decisions and negotiations, the limits to our cognitive resources shift us toward System 1 thought. This reliance on intuition that often comes with emotionally charged interactions (Loewenstein 1996) and with time pressure allows for the psychological biases that lead to irrationality, improper weighting of information (Petty and Cacioppo 1986; Petty and Wegner 1999), and sub-optimal outcomes.

Some intriguing recent work has suggested that our intuition - defined here as "a gut feeling based on unconscious past experience"- may indeed allow us to arrive at better decisions 
(Dijksterhuis and Nordgren 2006), particularly when it comes to complex decision problems. Others dispute the generalizability of these results (Payne, Samper, Bettman, and Luce 2008). Even proponents of such a definition of intuition acknowledge that both time and access to relevant information are necessary for quality decisions. But the role of intuition remains an interesting and controversial issue for negotiation researchers and practitioners.

\section{The Natural Negotiator}

Conventional wisdom has long maintained that some people are good negotiators and others are not (Thompson 2005, 2007) and that successful negotiation can be attributed primarily to natural skill or talent. But the teaching side of the negotiation field has developed around the idea that we can all learn to be better negotiators. Research has demonstrated the many ways in which negotiation outcomes may improve with training, including the greater likelihood of integrative agreements (Thompson 2005) and joint outcomes through knowledge transfer (Thompson, Gentner, and Loewenstein 2000), and the higher frequency of resolution under final-offer arbitration (Bazerman and Neale 1982). The benefits of training may also transfer over time; for example, skills learned through conflict resolution training may translate into changes in attitudes as perceived by individuals, and behaviors as perceived by both individuals and observers (Coleman and Lim 2001). Although work also suggests that the type of training may affect whether optimal settlements are reached (Van Boven and Thompson 2003), several lines of research, along with the popularity of training programs and MBA courses in negotiation, 
would suggest that negotiation skills and outcomes may generally be improved with training.

Despite our awareness of the positive impact of training on negotiation performance, implicit beliefs about skill and achievement may not necessarily match this explicit knowledge. In addition, recent research also challenges the role of training in negotiator performance, pointing to the importance of stable individual differences in explaining differences in objective outcomes (Elfenbein, Curhan, Eisenkraft, Shirako, and Brown 2009).

Other recent research suggests that it may also be important to consider how the mere perception of whether opponent negotiators are "naturals" or simply experienced may affect our assessment of their performance - and, in turn, contribute to suboptimal dyadic outcomes. Here, we focus not on the question of whether stable traits or training contribute more to outcomes or how much training may affect performance, but instead focus on our implicit beliefs about whether performance is rooted in training or nature.

Recent research suggests that our inclination to believe we are simply born with a fixed level of negotiation skill may be both tenacious and detrimental to negotiation outcomes; these entity theorists captured less of the bargaining surplus and were less integrative than those who believe skill level to be malleable (Kray and Haselhuhn 2007). The impact of such implicit theories about ability, however, may reach beyond the level of disposition. Laura Kray and Michael Haselhuhn demonstrate that such theories may also be induced, with similar effects on negotiation outcomes. Drawing from other new research on the evaluation of musicians and athletes, we have gained additional insight into the mistaken tendency to ascribe greater value, 
skill, and likelihood of success to more naturally gifted individuals, despite controlling for actual levels of performance (Tsay and Banaji 2009). This research suggests that domain experts are particularly vulnerable to this naturalness bias. Even as training creates better negotiators, they may also experience an increasing level of the bias. This may lead to the overvaluation of what opponent negotiators have to offer through inflated estimates of others' negotiation performance.

Such bias may also lead to an increased focus on characteristics of the negotiator or the negotiation process itself that may distract from a consideration of the issues that better allow for arrival at mutually beneficial trade-offs. Research on the perceived ability of mediators suggests that those seen as possessing high ability were more able to move negotiators toward the suggested solution and to arrive at better joint outcomes (Brookmire and Sistrunk 1980). Thus, the perception of an opponent negotiator as a "natural" - and, in turn, one with higher ability may yield worse outcomes for oneself, even if rates of impasse decrease.

\section{Conclusion}

Even as it has transitioned from decision analysis to behavioral decision research to social psychology, the decision perspective to negotiation has remained central to practitioners and academics alike, offering both practical relevance and the foundation for exciting new lines of research. Some of the most recent directions being pursued are surprises that early contributors to the decision perspective could have never predicted, as negotiation scholars engage with other 
disciplines and draw insights from diverse fields ranging from philosophy to neurobiology. We view this as a healthy sign for an ongoing line of negotiation research.

\section{References}

Adler, R., Rosen, B., and Silverstein, E. 1998. Emotions in negotiation: How to manage fear and anger. Negotiation Journal 14(2): 161-179.

Allred, K. G., Mallozzi, J. S., Matsui, F., and Raia, C. P. 1997. The influence of anger and compassion on negotiation performance. Organizational Behavior and Human Decision Processes 70(3): 175-187.

Ambady, N. and Rosenthal, R. 1992. Thin slices of expressive behavior as predictors of interpersonal consequences: A meta-analysis. Psychological Bulletin 111(2): 256-274.

Babcock, L. and Loewenstein, G. 1997. Explaining bargaining impasse: The role of self-serving biases. The Journal of Economic Perspectives, 11(1): 109-126.

Babcock, L., Loewenstein, G., Issacharoff, S., and Camerer, C. 1995. Biased judgments of fairness in bargaining. The American Economic Review 85(5): 1337-1343.

Banaji, M. R., Bazerman, M. H., and Chugh, D. 2003. How (un)ethical are you? Harvard Business Review 81(12): 56-64.

Barley, S. R. 1991. Contextualizing conflict: Notes on the anthropology of dispute and negotiation. In M. H. Bazerman, R. Lewicki and B. Sheppard, eds. Handbook of research 
in negotiation (vol. 3). Greenwich, CT: JAI Press.

Barry, B. 1999. The tactical use of emotion in negotiation. In R. Bies and R. Lewicki, eds. Research in negotiation in organizations (vol. 7): 93-121).

Barsade, S. 2002. The ripple effect: Emotional contagion and its influence on group behavior. Administrative Science Quarterly 47(4): 644-675.

Barsade, S. and Gibson, D. 2007. Why does affect matter in organizations? Academy of Management Perspectives 21(1): 36-59.

Bazerman, M. H. and Carroll, J. S. 1987. Negotiator cognition. In B. Staw and L. L. Cummings, eds. Research in Organizational Behavior (vol. 9):, 247-288. Greenwich, CT JAI Press.

Bazerman, M. H. and Chugh, D. 2006. Bounded awareness: Focusing failures in negotiation. In L. Thompson, ed. Negotiation Theory and Research: 7-26. New York: Psychology Press.

Bazerman, M. H., Magliozzi, T., and Neale, M. A. 1985. The acquisition of an integrative response in a competitive market. Organizational Behavior and Human Decision Processes 35(3) : 294-313.

Bazerman, M. H. and Moore, D. 2008. Judgment in managerial decision making (7th ed.). New York: John Wiley and Sons.

Bazerman, M. H. and Neale, M.A. 1983. Heuristics in negotiation: Limitations to effective dispute resolution. In M. H. Bazerman and R. J. Lewicki, eds. Negotiating in organizations. Beverly Hills, CA: Sage Publications, Inc. 
Bazerman, M. H. and Neale, M. A. 1992. Negotiating rationally. New York, NY: Free Press.

Bechara, A. and Damasio, A. 2005. The somatic marker hypothesis: A neural theory of economic decision. Games and Economic Behavior 52(2): 336-372.

Blount, S. and Bazerman, M. H. 1996. Inconsistencies in valuing comparative payoffs: Implications for bargaining and trade. Journal of Economic Behavior and Organizations, 30(2): 227-240.

Brookmire, D. A. and Sistrunk, F. 1980. The effect of perceived ability and impartiality of mediators and time pressure on negotiation. The Journal of Conflict Resolution 24(2): 311-327.

Carnevale, P. J. and Isen, A. M. 1986. The influence of positive affect and visual access on the discovery of integrative solutions in bilateral negotiations. Organizational Behavior and Human Decision Processes 37: 1-13.

Coleman, P. T. and Y. Y. J. Lim. 2001. A systematic approach to evaluating the effects of collaborative negotiation training on individuals and groups. Negotiation Journal 17: 363-392.

Damasio, A.R. 1994. Descartes' error: Emotion, reason, and the human brain. New York: Putnam.

Dees, J. G. and Cramton, P. C. 1991. Shrewd bargaining on the moral frontier: Toward a theory of morality in practice. Business Ethics Quarterly 1: 135-167. 
Dees, J. G. and Cramton, P. C. 1995. Deception and mutual trust: A reply to Strudler. Business Ethics Quarterly 5: 823-832.

Diekmann, K. A., Samuels, S. M., Ross, L., and Bazerman, M. H. 1997. Self-interest and fairness in problems of resource allocation: Allocators versus recipients. Journal of Personality and Social Psychology, 72(5): 1061-1074.

Dijksterhuis, A. and Nordgren, L.F. 2006. A theory of unconscious thought. Perspectives on Psychological Science 1: 95-109.

Elfenbein, H., Curhan, J., Eisenkraft, N., Shirako, A., and Brown, A. 2009. Why are some negotiators better than others? Opening the black box of bargaining behaviors. Available at SSRN: http://ssrn.com/abstract=1336257.

Fisher, R. and Ury, W. 1981. Getting to yes. Boston: Houghton Mifflin.

Follet, M. 1940. Constructive conflict. In H. Metcalf and L. Urwick, eds. Dynamic administration. New York: Harper and Row.

Forgas, J. P. 1998. On feeling good and getting your way: Mood effects on negotiator cognition and bargaining strategies. Journal of Personality and Social Psychology 74(3): 565-577.

Forgas, J.P. and George, J. M. 2001. Affective influences on judgments and behavior in organizations: An information processing perspective. Organizational Behavior and Human Decision Processes 86: 3-34.

Greenhalgh, L. and Chapman, D. I. 1995. Joint decision making: The inseparability of 
relationships and negotiation. In R. Kramerand D. Messick ., eds. Negotiation as a social process: New trends in theory and research: 166-185. Thousand Oaks, CA: Sage.

Hatta, T., Ohbuchi, K., and Fukuno, M. 2007. An experimental study on the effects of exitability and correctability on electronic negotiation. Negotiation Journal 23(3): 283-306.

Isen, A. M. and Baron, R. A. 1991. Positive affect as a factor in organizational behavior. Research in Organizational Behavior 13: 1-53.

Kahneman, D. and Tversky, A. 1979. Prospect theory: An analysis of decision under risk. Econometrica 47: 263-291.

Keltner, D. and Kring, A. M. 1998. Emotion, social function, and psychopathology. Review of General Psychology 2(3): 320-342.

Keltner, D. and Robinson, R. J. 1993. Imagined ideological differences in conflict escalation and resolution. International Journal of Conflict Management 4(3): 249-262.

Kramer, R. M. 1994. Self-enhancing cognitions and organized conflict. Unpublished manuscript.

Kramer, R. M., Newton, E., and Pommerenke, P. L. 1993. Self-enhancement biases and negotiator judgment: Effects of self-esteem and mood. Organizational Behavior and Human Decision Processes 56(1): 110-133.

Kray, L. and Haselhuhn, M. 2007. Implicit negotiation beliefs and performance: Experimental and longitudinal evidence. Journal of Personality and Social Psychology 93 (1): 49-64.

Krumhuber, E., Manstead, A., Cosker, D., Marshall, D., Rosin, P., and Kappas, A. 2007. Facial 
dynamics as indicators of trustworthiness and cooperative behavior. Emotion 7(4): 730-5.

Larrick, R. P. and Blount, S. 1997. The claiming effect: Why players are more generous in social dilemmas than in ultimatum games. Journal of Personality and Social Psychology 72(4): 810-825.

Lax, D. A. and Sebenius, J. K. 1986. The manager as negotiator. New York: Free Press.

Lerner, J. S., Small, D., and Loewenstein, G. 2004. Heart strings and purse strings: Carryover effects of emotions on economic transactions. Psychological Science 15(5): 337-341.

Lewicki, R. J. and Stark, N. 1996. What is ethically appropriate in negotiations: An empirical examination of bargaining tactics. Social Justice Research 9(1): 69-95.

Loewenstein, G. 1996. Out of control: Visceral influences on behavior. Organizational Behavior and Human Decision Processes 65(3): 272-292.

Loewenstein, G. F., Thompson, L., and Bazerman, M. H. 1989. Social utility and decision making in interpersonal contexts. Journal of Personality and Social Psychology 57(3): 426-441.

March, J. G., and Simon, H. A. 1958. Organizations. New York: John Wiley and Sons.

Menkel-Meadow, C., and Wheeler, M., eds. 2004. What's fair? Ethics for negotiators. San Francisco: Jossey-Bass.

Messick, D. M., Bloom, S., Boldizar, J. P., and Samuelson, C. D. 1985. Why we are fairer than others. Journal of Experimental Social Psychology 21(5): 480-500. 
Messick, D. M. and Sentis, K. P. 1983. Fairness, preference, and fairness biases. In D. M. Messick and K. S. Cook, eds. Equity theory: Psychological and sociological perspectives :61-64. New York: Praeger.

Morris, M. W., Sim, D. L., and Girotto, V. 1998. Distinguishing sources of cooperation in the one-round prisoner's dilemma: Evidence for cooperative decisions based on the illusion of control. Journal of Experimental Social Psychology 34(5): 494-512.

Neale, M. A. 1984. The effects of negotiation and arbitration cost salience on bargainer behavior: The role of the arbitrator and constituency on negotiator judgment. Organizational Behavior and Human Decision Processes 34(1): 97-111.

Neale, M. A. and Bazerman, M. H. 1985. The effects of framing and negotiator overconfidence on bargaining behaviors and outcomes. Academy of Management Journal 28(1): 34-49.

Northcraft, G. B. and Neale, M. A. 1987. Experts, amateurs, and real estate: An anchoring-andadjustment perspective on property pricing decisions. Organizational Behavior and Human Decision Processes 39(1): 84-97.

Payne, J. W., Samper, A., Bettman, J. R., and Luce, M. F. 2008. Boundary conditions on unconscious thought in decision making. Psychological Science 19(11): 1118-1123.

Petty, R. E. and Cacioppo, J. T. 1986. Communication and persuasion: Central and peripheral routes to attitude change. New York: Springer-Verlag.

Petty, R. and Wegner, D. 1999. The elaboration likelihood model: Current status and 
controversies. New York: The Guilford Press.

Pillutla, M. M. and Murnighan, J. 1996. Unfairness, anger, and spite: Emotional rejections of ultimatum offers. Organizational Behavior and Human Decision Processes 68(3): 208224.

Radzevick, J. R. and D. A. Moore. 2008. Myopic biases in competitions. Organizational Behavior and Human Decision Processes 107: 206-218.

Raiffa, H. 1982. The art and science of negotiation. Cambridge, MA: Harvard University Press/Belknap.

Robinson, R. J. and Friedman, R. A. 1995. Mistrust and misconstrual in union-management relationships: Causal accounts in adversarial contexts. International Journal of Conflict Management 6(3): 312-327.

Ross, L. and Samuels, S. M. 1993. The predictive power of personal reputation versus labels and construal in the prisoners” dilemma game. Unpublished manuscript, Palo Alto, CA (Stanford University).

Ross, L. and Stillinger, C. 1991. Barriers to conflict resolution. Negotiation Journal 7(4): 389404.

Ross, L. and Ward, A. 1995. Psychological barriers to dispute resolution. In M. P. Zanna, Ed. Advances in experimental social psychology (vol 27): 255-304. San Diego, CA: Academic Press. 
Ross, L. and Ward, A. 1996. Naive realism: Implications for social conflict and misunderstanding. In T. Brown, E. Reed, and E. Turiel, eds. Values and knowledge: 103135. Hillsdale, NJ: Lawrence Erlbaum Associates.

Rubin, J. Z. and Brown, B. R. 1975. The social psychology of bargaining and negotiation. New York: Academic Press.

Samuelson, W. F. and Bazerman, M. H. 1985. The winner's curse in bilateral negotiations. In V. Smith, ed. Research in Experimental Economics (vol. 3). Greenwich, CT: JAI Press.

Shafir, E. and Tversky, A. 1992. Thinking through uncertainty: Nonconsequential reasoning and choice. Cognitive Psychology 24(4): 449-474.

Stanovich, K. E. and West, R. F. 2000. Individual differences in reasoning: Implications for the rationality debate. Behavioral and Brain Sciences 23(5): 645-665.

Strudler, A. 1995. On the ethics of deception in negotiation. Business Ethics Quarterly 5(4): 805822.

Taylor, S. E. 1989. Positive illusions: Creative self-deception and the healthy mind. New York: Basic Books.

Tenbrunsel, A. E. 1998. Misrepresentation and expectations of misrepresentation in an ethical dilemma: The role of incentives and temptation. Academy of Management Journal 41(3): 330-339. 
Tenbrunsel, A. E. and Messick, D. M. 2004. Ethical fading: The role of self deception unethical behavior. Social Justice Research 17(2): 223-236.

Tenbrunsel, A. E., Wade-Benzoni, K. A., Moag, J., and Bazerman, M. H. 1999. The negotiation matching process: Relationships and partner selection. Organizational Behavior and Human Decision Processes 80(3): 252-284.

Thompson, L. L. 2005. The mind and heart of the negotiator (3rd ed.).Upper Saddle River, NJ: Pearson/Prentice Hall.

Thompson, L. L. 2007. The truth about negotiations. New York: The Financial Times Press.

Thompson, L., Gentner, D., and Loewenstein, J. 2000. Avoiding missed opportunities in managerial life: Analogical training more powerful than individual case training. Organizational Behavior and Human Decision Processes 82(1): 60-75.

Thompson, L. and Loewenstein, G. 1992. Egocentric interpretations of fairness and interpersonal conflict. Organizational Behavior and Human Decision Processes 51(2): 176-197.

Thompson, L. L., Nadler, J., and Kim, P. H. 1999. Some like it hot: The case for the emotional negotiator. In Thompson, L. and Levine, J. M., eds.; Shared cognition in organizations: The management of knowledge: 139-161. Mahwah, NJ, US: Lawrence Erlbaum Associates Publishers.

Tsay, C. and Banaji, M. 2009. Naturals and strivers: Preferences, beliefs and behavior about innate versus learned sources of achievement. Unpublished manuscript. 
Tversky, A. and Kahneman, D. 1974. Judgment under uncertainty: Heuristics and biases. Science 185(4157): 1124-1131.

Valley, K. L., Moag, J., and Bazerman, M. H. 1998. A matter of trust: Effects of communication on efficiency and distribution of outcomes. Journal of Economic Behavior and Organizations 34(2): 211-238.

Valley, K. L., Thompson, L. L., Gibbons, R., and Bazerman, M. H. 2002. How communication improves efficiency in bargaining games. Games and Economic Behavior 38(1): 127155.

Van Boven, L. and Thompson, L. 2003. A look into the mind of the negotiator: Mental models in negotiation. Group Processes and Interpersonal Relations 6(4) : 387-404.

Walton, R. E. and McKersie, R. B. 1965. A behavioral theory of labor negotiation. New York: McGraw-Hill.

Willis, J. and Todorov, A. 2006. First impressions: Making up your mind after a 100-ms exposure to a face. Psychological Science 17(7)=: 592-598. 